\title{
Neonatal Hemolytic Jaundice: Morphologic Features of Erythrocytes That Will Help You Diagnose the Underlying Condition
}

\author{
Robert D. Christensen Hassan M. Yaish Richard S. Lemons \\ Women and Newborns Program, Intermountain Healthcare, and Division of Hematology/Oncology, Department of \\ Pediatrics, University of Utah School of Medicine, Salt Lake City, Utah, USA
}

\author{
Key Words \\ Erythrocyte · Kernicterus · Jaundice · Neonate $\cdot$ Hemolysis . \\ Glucose 6-phosphate dehydrogenase
}

\begin{abstract}
Background: Many cases of severe neonatal hyperbilirubinemia never have the underlying cause of the jaundice clearly identified. Thus they are said to have 'idiopathic' severe neonatal jaundice. However, finding the exact cause, if it is a genetic condition, can enable informed anticipatory guidance regarding future episodes of hemolysis, anemia, or bilirubin cholelithiasis. Objective: 'Next generation' gene sequencing can often reveal the mutations responsible for severe neonatal hyperbilirubinemia, but wisely using this new technology involves selective application, employing this testing only if inexpensive technology fails to reveal the diagnosis. Methods: In this review, we display and discuss five types of red blood cell morphological abnormalities that have helped us categorize cases of neonatal hemolytic jaundice. Results: As an aid to applying inexpensive technology, we review morphological abnormalities of erythrocytes that are easily identified on a blood film. When found, these abnormalities can be important clues to the underlying hemolytic condition giving rise to neonatal jaundice. Conclusions: Applying these simple and inexpensive methods can assist neonatologists in caring for neonates who have hemolytic
\end{abstract}

jaundice. We predict that by using these principles the term 'idiopathic' neonatal jaundice will become less common as the underlying causes are identified. @ 2014 S. Karger AG, Basel

\section{Introduction}

Severe jaundice is the most common condition requiring re-hospitalization during the first week after birth [1, 2]. Unfortunately, most neonates with extreme hyperbilirubinemia have no underlying etiology diagnosed to explain their jaundice. For example, we found that $66 \%$ of neonates with a total serum bilirubin (TSB) $>30 \mathrm{mg} / \mathrm{dl}$ had no etiology identified, and were termed 'idiopathic' neonatal jaundice [3]. This is comparable to a report from the USA kernicterus registry where $55 \%$ of neonates with kernicterus had no etiology reported [4].

Surely every neonate with a critically elevated TSB has underlying reasons for their extreme jaundice. We speculate that hemolysis underlies many cases currently termed idiopathic. This is supported by studies of Kaplan et al. [5] and Maisels and Kring [6]. The latter showed significantly elevated end-tidal carbon monoxide concentrations in neonates with a TSB $>75$ th percentile for age. In some cases hemolysis is limited to the newborn period, while in others it is part of a life-long disorder such as glucose 6-phosphate dehydrogenase (G6PD) deficiency [7], pyruvate ki-

\section{KARGER}

E-Mail karger@karger.com

www.karger.com/neo
(C) 2014 S. Karger AG, Basel

$1661-7800 / 14 / 1054-0243 \$ 39.50 / 0$
Dr. Robert D. Christensen

Women and Newborn's Clinical Program

Intermountain Healthcare

4401 Harrison Blvd, Ogden, UT 84403 (USA)

E-Mail rdchris4@ihc.com 
Table 1. Morphological abnormalities of erythrocytes, from neonates with unexplained severe jaundice, as a guide to discovering the underlying cause of hemolysis

\begin{tabular}{|c|c|c|c|}
\hline $\begin{array}{l}\text { Abnormal erythrocyte } \\
\text { morphology }\end{array}$ & Most likely cause(s) & $\begin{array}{l}\text { Suggested laboratory } \\
\text { testing/findings }\end{array}$ & Other features \\
\hline \multirow[t]{2}{*}{ Microspherocytes } & $\begin{array}{l}\text { Hereditary } \\
\text { spherocytosis }\end{array}$ & $\begin{array}{l}\text { DAT }(-) \\
\text { EMA flow }(+) \\
\text { Persistent spherocytosis }\end{array}$ & $\begin{array}{l}\text { MCHC/MCV elevated } \\
(>36, \text { likely }>40)[15]\end{array}$ \\
\hline & ABO hemolytic disease & $\begin{array}{l}\text { DAT }(+) \\
\text { Transient spherocytosis }\end{array}$ & $\begin{array}{l}\text { MCHC/MCV normal } \\
(<36, \text { likely }<34)\end{array}$ \\
\hline \multirow[t]{2}{*}{ Bite and blister cells } & G6PD deficiency & G6PD enzyme activity & \multirow{2}{*}{$\begin{array}{l}\text { Typically male } \\
\text { Ethnicity of equatorial origin }\end{array}$} \\
\hline & Unstable hemoglobin & Heinz body prep & \\
\hline Echinocytes & PK deficiency & PK enzyme activity & $\begin{array}{l}\text { Autosomal recessive, likely to } \\
\text { have no family history }\end{array}$ \\
\hline \multirow{4}{*}{ Schistocytes } & ADAMTS13 deficiency & $\begin{array}{l}\text { Severely decreased ADAMTS13 activity } \\
(<0.1 \mathrm{U} / \mathrm{ml})\end{array}$ & \multirow{4}{*}{$\begin{array}{l}\text { Low or falling platelet count } \\
\text { Normal to high IPF } \\
\text { Normal to high MPV DIC, } \\
\text { perinatal asphyxia, ADAMTS13 } \\
\text { deficiency, early neonatal HUS, } \\
\text { and giant hemangiomas all } \\
\text { involve platelet consumption from } \\
\text { endothelial injury and all have a } \\
\text { similar neonatal presentation }\end{array}$} \\
\hline & Neonatal hemolytic uremic syndrome & Acute renal failure & \\
\hline & Homozygous protein $\mathrm{C}$ deficiency & $\begin{array}{l}\text { Severely decreased functional Protein } \mathrm{C} \\
\text { activity }(<1 \%)\end{array}$ & \\
\hline & Giant hemangioma & May be internal or external & \\
\hline
\end{tabular}

$\mathrm{IPF}=$ Immature platelet fraction; MPV = mean platelet volume; FV = factor 5; FVIII = factor 8.

nase (PK) deficiency [8], or a red cell membrane defect [9]. When neonates need emergent treatment for severe jaundice, perhaps the emphasis on getting the TSB down to safe levels sometimes eclipses the need to discover why it became so high in the first place, and consequently inadequate effort is put into a diagnostic endeavor.

Diagnosing the cause of severe jaundice early on can be of value. For instance, discovering G6PD deficiency prompts warnings to avoid oxidant stressors in the form of food, medicines, or viral infections. Since hyperbilirubinemia in neonates with G6PD deficiency frequently occurs with no clear offending factor, just knowing the condition exists can prompt close monitoring and expectant care. Also, when a diagnosis of chronic hemolytic jaundice is made, anticipatory guidance can be provided regarding the likelihood of anemia during childhood and early bilirubin cholelithiasis.

An underlying condition causing neonatal hemolysis can be searched for by functional assays, and exact mutations can be identified using 'next generation' gene sequencing [10]. However, simply examining the blood smear can be an inexpensive and rapid initial step, sometimes making more expensive testing unnecessary. To assist neonatologists accomplish this we compiled this review of common RBC morphological abnormalities causing neonatal hemolytic jaundice. When the morphological finding is combined with the family history and basic laboratory evaluation, most cases of hemolytic jaundice can be recognized and the cause categorized. In this review we will not cover all morphological disorders of erythrocytes, such as hereditary stomatocytosis/xerocytosis, or conditions associated with excessive target cells or acanthocytes. Readers are referred to excellent reviews of these abnormalities $[11,12]$.

\section{Considering Hemolysis as a Causative Mechanism (table 1)}

Hemolysis should be a prime consideration whenever hyperbilirubinemia occurs 'early', namely when the TSB exceeds the 95th percentile hour-specific nomogram val- 
ue on the first day following birth [1]. Simple ways to support a diagnosis of hemolysis include finding hemoglobin without erythrocytes in the urine on a standard urine analysis and finding pink serum on a visual examination of a blood sample. Also, the absence of haptoglobin in the serum can be tested rapidly and inexpensively and supports a diagnosis of hemolysis $[13,14]$. However, haptoglobin levels can be low in neonates without hemolysis, thus haptoglobin analysis alone can be an unreliable parameter for judging neonatal hemolysis.

Accurately quantifying carbon monoxide in exhaled breath can be a precise method for detecting hemolysis $[5,6]$. Although no clinical tool is commercially available for this in neonates and children unable to give a forced exhalation, a promising tool, CoSense by Capnia, Inc. (Palo Alto, Calif., USA) has recently been cleared in the USA, received a CE mark in Europe, and is under investigation in neonatal patients by our group and others (clinicaltrials.gov/show/NCT01848691).

In cases of severe neonatal hemolysis with a negative direct Coomb's test (DAT), if a transfusion is deemed urgently needed, we strongly advise neonatologists to draw blood into an EDTA-anticoagulated tube prior to transfusion for morphological analysis and specialized hematological testing. When examined by a skilled technician, the erythrocyte morphology on a routine or supravital-stained blood smear can provide important insights into the cause of hemolysis. The technologist should identify and record these abnormalities in the comments section of the CBC. However, neonatologists can examine the blood film themselves or can ask a pediatric hematologist for assistance in reviewing the smear, looking for these morphological findings. Below, we provide illustrations and descriptions we have found to be particularly informative.

\section{Microspherocytes}

Spherocytes (fig. 1) are identified by the lack of a central zone of pallor, characteristic of normal erythrocytes. Spherocytes have lost part of the cell membrane, and are characterized by a low mean corpuscular volume (MCV) with a normal hemoglobin content leading to an elevated mean corpuscular hemoglobin concentration (MCHC) [15]. When abundant spherocytes are observed on the smear of a neonate who has severe jaundice, two main entities should be considered; $\mathrm{ABO}$ hemolytic disease and hereditary spherocytosis (HS). Although the DAT is generally positive in the former and negative in the latter, there may rarely be a jaundiced neonate with $\mathrm{ABO}$ hemo-

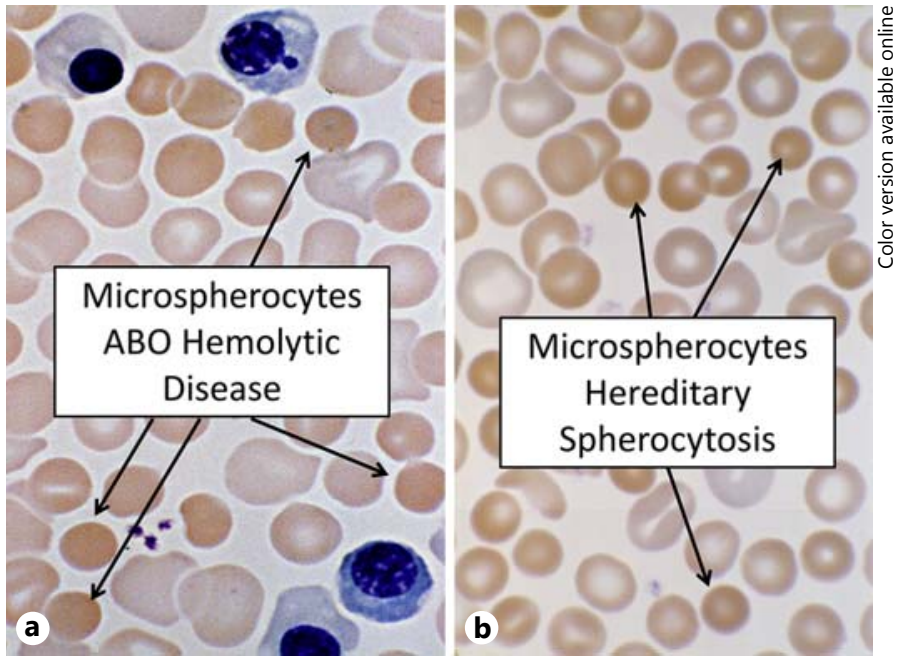

Fig. 1. Microspherocytes. a Neonate with ABO hemolytic disease. b Neonate with HS.

lytic disease with a negative Coombs test, because of insufficient maternal antibody to render the Coombs test positive but still sufficient to result in some degree of hemolysis [16]. Also, the DAT is sometimes negative but the indirect Coombs is positive.

The spherocytosis of ABO hemolytic disease will diminish over the first weeks and should be completely resolved 1 or 2 months after birth. In contrast, spherocytes in neonates with HS persist. When the mother is group $\mathrm{O}$, the baby A or B, the DAT positive, and the baby has early hyperbilirubinemia, a blood smear may not be needed to make the diagnosis. However, we recently had a case of $\mathrm{O} / \mathrm{B}$ hemolytic jaundice where the hyperbilirubinemia was so severe (TSB $41.7 \mathrm{mg} / \mathrm{dl}$ ) that we deemed additional investigation needed, and indeed HS due to a mutation in SLC4A1 was also found [17]. The search was triggered because very large numbers of spherocytes were seen which is not usually the case in isolated $\mathrm{ABO}$ hemolytic jaundice.

About $65-70 \%$ of neonates with HS inherit the condition in autosomal dominant fashion, thus a parent carries this diagnosis. However, sometimes a parent with HS is unaware of their own HS diagnosis [11]. This is more common with a mild phenotype, or a parent that had severe jaundice only during the neonatal period. Of the remaining $30-35 \%$ of $\mathrm{HS}$ cases, some are de novo mutations and some are autosomal recessive varieties $[11,18]$.

We do not advocate obtaining an erythrocyte osmotic fragility test to confirm HS in a neonate. This test can be expensive and is frequently negative (normal) in a neonate with HS, only to become positive (increased fragility) after 


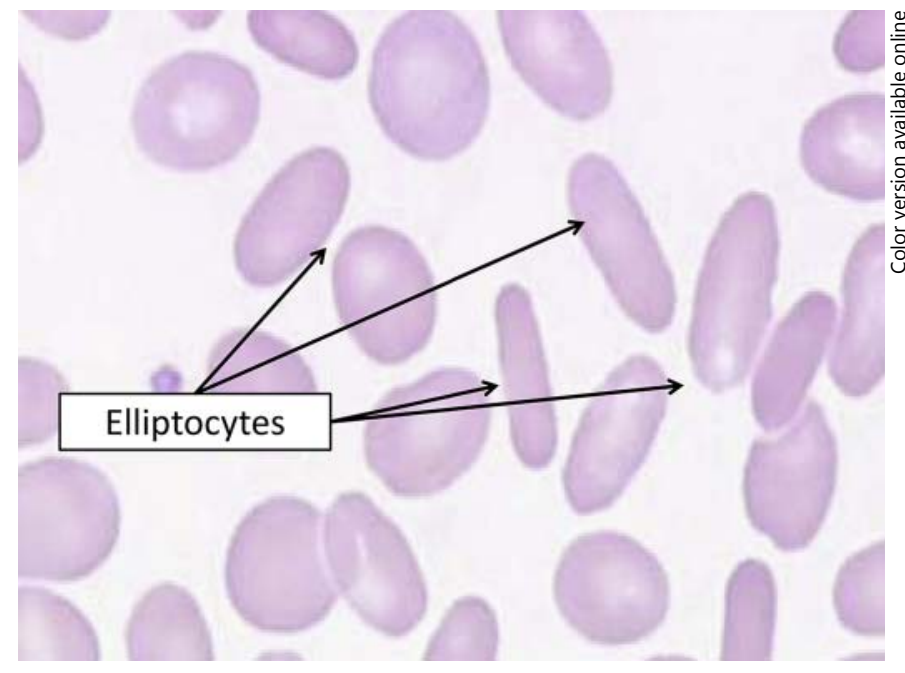

Fig. 2. Elliptocytes.

several months of age. The explanation for the frequently false-negative test in neonates involves the physiologically reduced erythrocyte osmotic fragility typical of the neonatal period, because the erythrocytes are more elastic and capable of expanding in a hypotonic environment without lysing [11]. Therefore a 'normal' osmotic fragility test result in a neonate with HS is common. If a confirmatory test for HS is needed, we prefer either (1) waiting for 3-4 months to perform the osmotic fragility test, (2) performing an acidified glycerol lysis test [19] or (3) performing an eosin-5-maleimide (EMA) flow, which involves stoichiometric binding of eosin dye to Band-3 on the surface of erythrocytes. Using EMA-flow cytometry, neonates with $\mathrm{HS}$ can be identified by a binding pattern outside the normal 'footprint' $[17,20]$.

It is possible to determine the exact mutation in neonates to HS. However, doing so is expensive and usually adds little to the clinical care. We test for the exact mutation only in atypical or particularly severe neonatal HS cases $[17,18,21]$.

\section{Elliptocytes}

Erythrocytes with an oval or elliptical shape (fig. 2) generally occur as an autosomal dominantly inherited condition, with a variety of genotypes, and with phenotypes ranging from completely asymptomatic to moderately severe hemolytic anemia [22]. Mutations causing this condition result in a particular type of erythrocyte cytoskeletal instability. Erythrocytes are constantly under

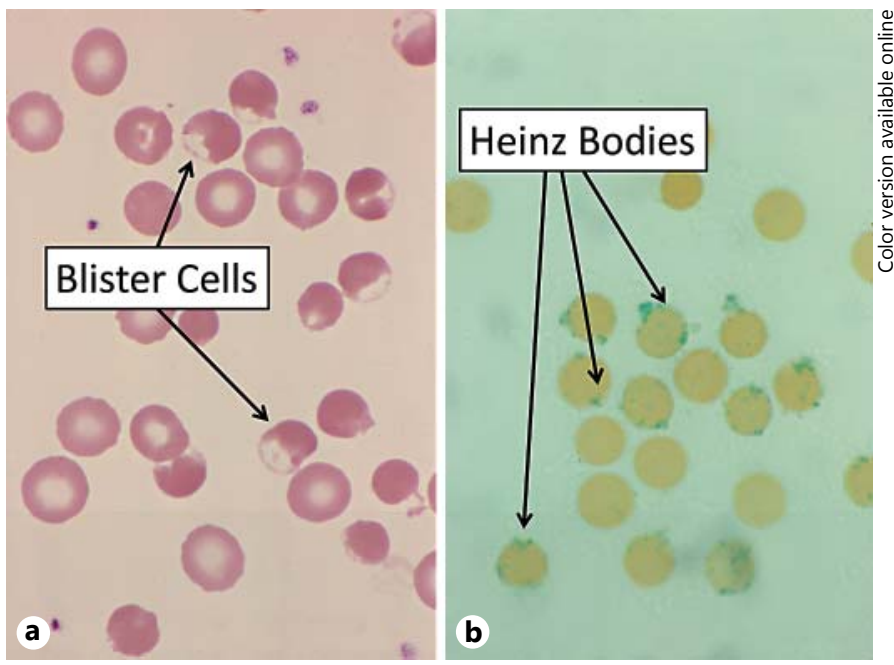

Fig. 3. Bite or blister cells. a Blister cells from a neonate with G6PD deficiency. b Heinz bodies from a neonate with G6PD deficiency.

the influence of deforming forces as they traverse capillary spaces with a diameter narrower than themselves. They deform to pass through these space, but reform into biconcave discs once they traverse the capillary. However in hereditary elliptocytosis (HE) the deformation renders the cell permanently elliptical and these abnormally shaped cells can be culled by the spleen, shortening their survival [22].

Unlike neonates with HS, neonates with HE lack distinctive RBC indices and are identified only by examining a blood smear. Most neonates with HE do not have significant jaundice or anemia and the condition commonly goes undetected in the neonatal period. However, an important exception, often resulting in severe neonatal jaundice, occurs when a neonate inherits a HE mutation from one parent, and also inherits a different RBC membrane defect from the other parent, similar to an autosomal recessive condition. We recently reported such a neonate in detail [23] with a condition termed pyropoikilocytosis.

\section{Bite and Blister Cells}

These terms are cleverly descriptive; a bite cell appears to have a mouth-shaped bite taken from it. Blister cells are often seen in the company of bite cells (fig. 3). It is a cell which has lost a small portion of the hemoglobin content leaving an empty space covered by a thin outer membrane, resembling a blister on the surface of the erythrocytes $[24,25]$. When bite and blister cells are observed in 
the smear of a neonate who has severe jaundice, the conclusion can be drawn that hemoglobin has precipitated at or near the membrane and that the precipitate (Heinz body) has been removed by reticuloendothelial cells. Conditions resulting in neonatal bite and blister cells include acute hemolysis triggered by unstable hemoglobins (such as hemoglobin F Poole - a $\gamma$-globin mutation, or hemoglobin Hasharon - an a-globin mutation) [26]. Bite and blister cells can also be generated when G6PD or (much less commonly) other enzymes in the same pathway are deficient resulting in hemolytic crisis [27]. This does not occur with deficient enzymes in the glycolytic pathway (such as PK deficiency), which have their own characteristic morphological findings.

When bite and blister cells are observed, G6PD deficiency is a prime consideration, particularly if the neonate is a male and of equatorial ancestry. However, most cases of G6PD deficiency in a neonate do not have bite or blister cells. We advocate measuring G6PD enzymatic activity in all cases of unexplained severe neonatal hyperbilirubinemia. One has to keep in mind that, based on the severity of the defect, significantly elevated reticulocyte counts can render the G6PD enzymatic assay falsely negative, because reticulocytes are richly endowed with G6PD activity. Therefore, borderline low G6PD enzymatic activity in a neonate with marked reticulocytosis and bite and/or blister cells should be interpreted as possible G6PD deficiency and this can be confirmed later when the reticulocyte count is normal. Females should not be excluded from consideration because of 'lyonization' [28].

\section{Echinocytes}

Echinocytes, as shown in figure 4, are contracted and dehydrated cells with numerous rather uniform spicules. Sometimes echinocytes on a blood film are an artifact, but when the blood of a neonate with hemolytic jaundice has several echinocytes per high-power field throughout the blood film, associated with polychromasia, the finding is usually significant. When erythrocytes lack sufficient ATP to operate cell-surface ion-exchange pumps, the cells can become crenated giving rise to some shriveled appearing cells with spicules $[8,11]$. In our experience, PK deficiency is the most common condition in jaundiced neonates giving rise to these cells. Less common causes of energy failure, such as glucose-phosphate isomerase and phosphofructokinase deficiency, can also cause prominent echinocytosis [8].

Neonatal Hemolytic Jaundice

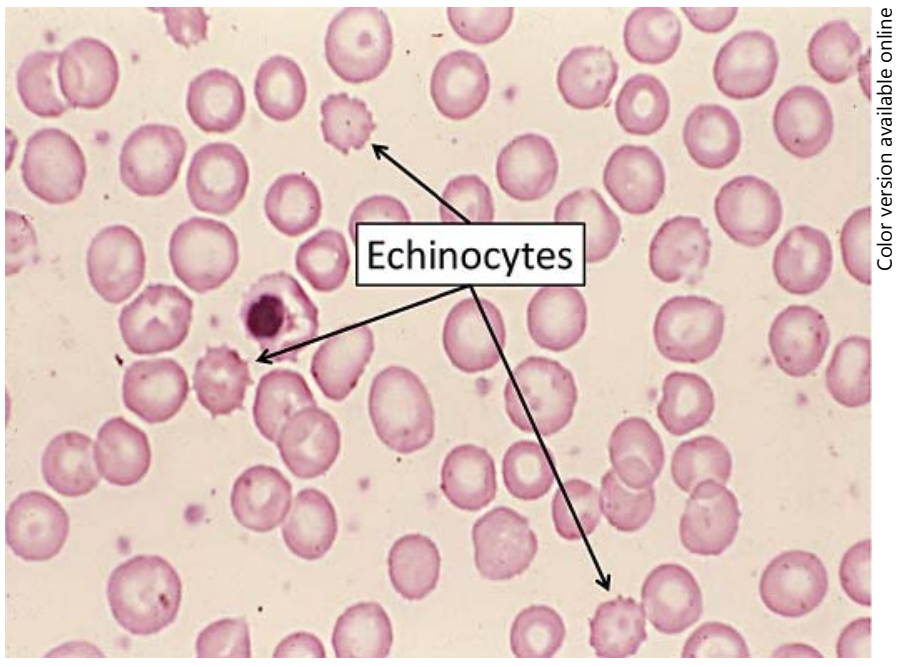

Fig. 4. Echinocytes from a neonate with PK deficiency.

Erythrocyte PK enzymatic activity can be quantified inexpensively using small quantities of blood. PK deficiency is an autosomal recessive condition; generally the neonate is a compound heterozygote, inheriting one PK gene mutation from one parent and a different mutation in the same gene from the other parent [8]. Exceptions occur in consanguineous kindreds where the same mutation is inherited from an asymptomatic mother and an asymptomatic father, thus the neonate is a homozygote for the mutation [29]. In general, we do not seek to identify the exact mutation(s) responsible for neonates with PK deficiency. Exceptions occur as part of epidemiological studies and when the phenotype is particularly severe [29].

\section{Schistocytes}

Fragments of erythrocytes, as shown in figure 5, are termed schistocytes. These suggest mechanical destruction of red cells within the vasculature. Schistocytes are not uniform in size or shape, often have a small and jagged appearance, and lack central pallor. Among neonates with severe jaundice, schistocytes on the blood film can be an artifact. However, if several schistocytes are seen per high-power field throughout the blood film accompanying normal erythrocytes, a microangiopathic condition is likely. Intravascular fibrin strands, as can occur in disseminated intravascular coagulation (DIC), or large hemangiomas can cause schistocytosis when circulating erythrocytes undergo traumatic mechanical disruption. 


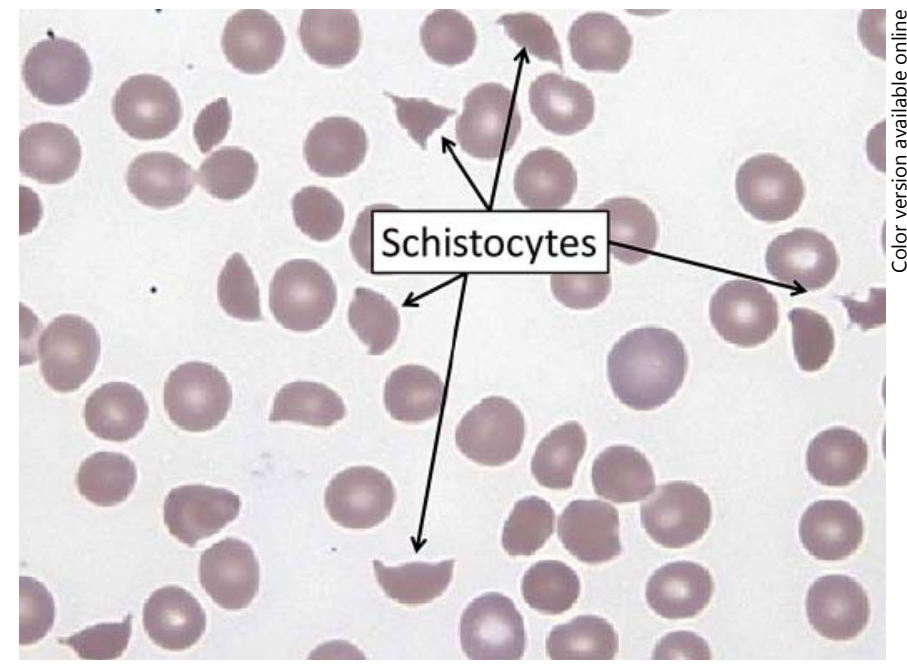

Fig. 5. Schistocytes from a neonate with DIC associated with birth asphyxia.

Automated or manual differential counting of schistocytes has been recommended, but is not yet commonly practiced, and reference intervals are not available for neonatal subjects [30]. General guidelines recommend that if $>1 \%$ of erythrocytes on a blood film of a full-term neonates are schistocytes, or if $>5 \%$ schistocytes are found from a premature baby, the term 'schistocytosis' is appropriate. Specific cell shapes qualifying for inclusion under the term 'schistocyte' include the following:

- Small fragments with sharp angles or spines (triangular) and straight or distorted cytoplasmic borders; usually staining darkly, occasionally pale.

- Microcrescents, which are similar to triangular forms but with a round contour on one side.

- Helmet cells, which show an amputated zone of cytoplasm with a straight border and sharp angles.

- Keratocytes, which show prominent spicules surrounding a concave border.

- Microspherocytes (small darkly-staining spheres without central pallor) should only be counted as schistocytes in the presence of the other schistocyte shapes.

The primary value of quantifying schistocytes in a jaundiced neonate is to confirm the presence of a microangiopathic condition. When thrombocytopenia is found in a jaundiced neonate with schistocytosis several clinical conditions should be considered: (1) DIC, which can accompany perinatal asphyxia, sepsis, or other infections [31]; (2) a congenital form of thrombotic thrombocytopenic purpura due to deficiency of the von Willebrand factor cleaving protease ADAMTS13 [31-34]; (3) homo- zygous protein C deficiency [35]; (4) neonatal hemolytic uremic syndrome [36-39], and (5) giant hemangioma or vascular tumors [40].

\section{Conclusion}

Improving the quality of healthcare is accomplished not only when discoveries improve outcomes, but also when costs of care are contained or lowered [41]. Applying new medical technologies can improve certain outcomes, but if those technologies have very high costs, their indiscriminant and wasteful use should be discouraged, assuming that inexpensive alternatives are available to achieve the same ends.

The skill of blood film analysis, once a routine part of a thorough physical examination, may not currently be taught or practiced as it once was [42]. Examination of a blood film is not only a means of identifying a hematological disorder causing hemolytic jaundice, but can also be a significant cost-cutting measure in reaching the correct diagnosis. Genetic diagnosis of the causes of hemolytic jaundice with high-throughput sequencing will soon be so informative and compelling as to potentially make blood film examination obsolete. With the belief that the wisest uses of any new technology include restraint and focus, we maintain that simple blood film analysis, looking for the morphological findings taught in this review will lead to the diagnosis of many jaundiced neonates who are currently labeled 'idiopathic'. Moreover, this approach can limit the indiscriminant use of expensive testing thereby constituting a step toward better healthcare value.

\section{Disclosure Statement}

The authors have no conflicts of interest to disclose.

References

$$
\begin{aligned}
& \text { Bhutani VK, Stark AR, Lazzeroni LC, Poland } \\
& \text { R, Gourley GR, Kazmierczak S, Meloy L, Bur- } \\
& \text { gos AE, Hall JY, Stevenson DK: Initial clinical } \\
& \text { testing evaluation and risk assessment for } \\
& \text { universal screening for hyperbilirubinemia } \\
& \text { Study Group. Predischarge screening for se- } \\
& \text { vere neonatal hyperbilirubinemia identifies } \\
& \text { infants who need phototherapy. J Pediatr } \\
& \text { 2013;162:477-482.e1. } \\
& \text { Bhutani VK, Stevenson DK: The need for } \\
& \text { technologies to prevent bilirubin-induced } \\
& \text { neurologic dysfunction syndrome. Semin } \\
& \text { Perinatol 2011;35:97-100. }
\end{aligned}
$$


>3 Christensen RD, Lambert DK, Henry E, Eggert LD, Yaish HM, Reading NS, Prchal JT: Unexplained extreme hyperbilirubinemia among neonates in a multihospital healthcare system. Blood Cells Mol Dis 2013;50:105-109.

-4 Johnson L, Bhutani VK, Karp K, Sivieri EM, Shapiro SM: Clinical report from the pilot USA kernicterus registry (1992 to 2004). J Perinatol 2009;29:S25-S45.

5 Kaplan M, Muraca M, Hammerman C, Rubaltelli FF, Vilei MT, Vreman HJ, Stevenson DK: Imbalance between production and conjugation of bilirubin: a fundamental concept in the mechanism of neonatal jaundice. Pediatrics 2002;110:e47-e49.

6 Maisels MJ, Kring E: The contribution of hemolysis to early jaundice in normal newborns. Pediatrics 2005;118:276-279.

7 Kaplan M, Muraca M, Vreman HJ, Hammerman C, Vilei MT, Rubaltelli FF, Stevenson DK: Neonatal bilirubin production-conjugation imbalance: effect of glucose-6-phosphate dehydrogenase deficiency and borderline prematurity. Arch Dis Child Fetal Neonatal Ed 2005;90:F123-F127.

8 Zanella A, Bianchi P, Fermo E: Pyruvate kinase deficiency. Haematologica 2007;92:721-723.

9 Mohandas N, Gallagher PG: Red cell membrane: past, present, and future. Blood 2008; 112:3939-3948.

10 Christensen RD, Nussenzveig RH, Yaish HM, Henry E, Eggert LD, Agarwal AM: Identifying causes of significant hyperbilirubinemia in neonates using 'next generation' gene sequencing. 2013, submitted.

11 Gallagher PG, Glader B: Hereditary spherocytosis, hereditary elliptocytosis, and other disorders associated with abnormalities of the erythrocyte membrane; in Greer JP, Foerster J, Rodgers GM, Paraskevas F, Glader B, Arber DA, Means RT Jr (eds): Wintrobe's Clinical Hematology, ed 12. Philadelphia, Lippincott/ Williams \& Wilkins, 2009, pp 911-932.

12 Bruce LJ: Hereditary stomatocytosis and cation-leaky red cells - recent developments. Blood Cells Mol Dis 2009;42:216-222.

13 Chavez-Bueno S, Beasley JA, Goldbeck JM, Bright BC, Morton DJ, Whitby PW, Stull TL: Haptoglobin concentrations in preterm and term newborns. J Perinatol 2011;31:500-503.

14 Cakmak A, Calik M, Atas A, Hirfanoglu I, Erel O: Can haptoglobin be an indicator for the early diagnosis of neonatal jaundice? J Clin Lab Anal 2008;22:409-414.

15 Yaish HM, Henry E, Baer VL, Bennett ST, 29 Christensen RD: A simple method of screening newborn infants for hereditary spherocytosis. J Appl Hematol 2013;4:27-32.

16 Herschel M, Karrison T, Wen M, Caldarelli L, Baron B: Isoimmunization is unlikely to be the cause of hemolysis in $\mathrm{ABO}$-incompatible but direct antiglobulin test-negative neonates. Pediatrics 2002;110:127-130.
17 Christensen RD, Yaish HM, Nussenzveig RH, Reading NS, Agarwal AM, Eggert LD, Prchal JT: Acute kernicterus in a neonate with $\mathrm{O} / \mathrm{B}$ blood group incompatibility and a mutation in SLC4A1. Pediatrics 2013;132:e531-e534.

18 Yaish HM, Christensen RD, Agarwal A: A neonate with Coombs-negative hemolytic jaundice with spherocytes but normal erythrocyte indices: a rare case of autosomal-recessive hereditary spherocytosis due to $\alpha$-spectrin deficiency. J Perinatol 2013;33:404-406.

19 Hoffmann JJ, Swaak-Lammers N, Breed WP, Strengers JL: Diagnostic utility of the pre-incubated acidified glycerol lysis test in haemolytic and non-haemolytic anaemias. Eur J Haematol 1991;47:367-370.

20 Kar R, Mishra P, Pati HP: Evaluation of eosin5-maleimide flow cytometric test in diagnosis of hereditary spherocytosis. Int J Lab Hematol 2010;32:8-16.

21 Christensen RD, Henry E: Hereditary spherocytosis in neonates with hyperbilirubinemia. Pediatrics 2010;125:120-125.

22 King MJ, Zanella A: Hereditary red cell membrane disorders and laboratory diagnostic testing. Int J Lab Hematol 2013;35:237-243.

23 Christensen RD, Nussenzveig RH, Reading NS, Agarwal AM, Prchal JT, Yaish HM: Variations in both $a$-spectrin (SPTA1) and $\beta$-spectrin (SPTB) in a neonate with prolonged jaundice in a family where nine individuals had hereditary elliptocytosis. Neonatology 2014;105:1-4.

24 Yoo D, Lessin LS: Drug-associated 'bite cell' hemolytic anemia. Am J Med 1992;92:243248.

25 Mishriki YY: What's eating these red blood cells? Drug-induced 'bite-cell' hemolytic anemia. Postgrad Med 1998;104:45-46.

26 Bender JW, Reilly MP, Asakura T: Molecular stability and function of hemoglobins Hasharon $\left(\alpha_{2} 47\right.$ (CD5)Asp-His- $\left.\beta_{2}\right)$ and Hasharon $\left(\alpha_{2} 47\right.$ (CD5)Asp-His- $\left.\delta_{2}\right)$. Hemoglobin 1984; 8:61-73.

27 Christensen RD, Yaish HM, Wiedmeier SE, Reading NS, Pysher TJ, Palmer CA, Prchal JT: Neonatal death suspected to be from sepsis was found to be kernicterus with G6PD deficiency. Pediatrics 2013;132:e1694-e1698.

28 Kaplan M, Beutler E, Vreman HJ, Hammerman C, Levy-Lahad E, Renbaum P, Stevenson DK: Neonatal hyperbilirubinemia in glucose6-phosphate dehydrogenase-deficient heterozygotes. Pediatrics 1999;104:68-74.

29 Christensen RD, Yaish HM, Johnson CB, Bianchi P, Zanella A: Six children with pyruvate kinase deficiency from one small town: molecular characterization of the PK-LR gene. J Pediatr 2011;159:695-697.

30 Zini G, d'Onofrio G, Briggs C, Erber W, Jou JM, Lee SH, McFadden S, Vives-Corrons JL, Yutaka N, Lesesve JF; International Council for Standardization in Haematology (ICSH): ICSH recommendations for identification, diagnostic value, and quantitation of schistocytes. Int J Lab Hematol 2012;34:107-116.
1 Motta M, Del Vecchio A, Radicioni M: Clinical use of fresh-frozen plasma and cryoprecipitate in neonatal intensive care unit. J Matern Fetal Neonatal Med 2011;24(suppl 1): 129-131.

32 Lotta LA, Garagiola I, Palla R, Cairo A, Peyvandi F: ADAMTS13 mutations and polymorphisms in congenital thrombotic thrombocytopenic purpura. Hum Mutat 2010;31: 11-19.

33 Schiff DE, Roberts WD, Willert J, Tsai HM: Thrombocytopenia and severe hyperbilirubinemia in the neonatal period secondary to congenital thrombotic thrombocytopenic purpura and ADAMTS13 deficiency. J Pediatr Hematol Oncol 2004;26:535-538.

34 Camilleri RS, Scully M, Thomas M, Mackie IJ, Liesner R, Chen WJ, Manns K, Machin SJ: A phenotype-genotype correlation of ADAMTS13 mutations in congenital thrombotic thrombocytopenic purpura patients treated in the United Kingdom. J Thromb Haemost 2012;10:1792-1801.

35 Salonvaara M, Kuismanen K, Mononen T, Riikonen P: Diagnosis and treatment of a newborn with homozygous protein $\mathrm{C}$ deficiency. Acta Paediatr 2004;93:137-139.

-36 Fallahpour M, Hafizi A, Fouladgar A, Rajabian B: Neonatal atypical hemolytic uremic syndrome may cause prenatal asphyxia. Arch Iran Med 2012;15:729-730.

37 Besbas N, Gulhan B, Karpman D, Topaloglu R, Duzova A, Korkmaz E, Ozaltin F: Neonatal onset atypical hemolytic uremic syndrome successfully treated with eculizumab. Pediatr Nephrol 2013;28:155-158.

38 Menni F, Testa S, Guez S, Chiarelli G, Alberti L, Esposito S: Neonatal atypical hemolytic uremic syndrome due to methylmalonic aciduria and homocystinuria. Pediatr Nephrol 2012;27:1401-1405.

39 Laurence J: Diagnosis of atypical hemolytic uremic syndrome: a review of case studies. Clin Adv Hematol Oncol 2012;10(suppl 17): 9-11.

40 Yohannan MD, Abdulla AM, Patel PJ: Neonatal hepatic haemangioendothelioma: presentation with jaundice and microangiopathic haemolytic anaemia. Eur J Pediatr 1990; 149:804-805

41 Cosgrove DM, Fisher M, Gabow P, Gottlieb G, Halvorson GC, James BC, Kaplan GS, Perlin JB, Petzel R, Steele GD, Toussaint JS: Ten strategies to lower costs, improve quality, and engage patients: the view from leading health system CEOs. Health Aff (Millwood) 2013;32: 321-327.

42 Perkins SL: Examination of the blood smear; in Greer JP, Foerster J, Rodgers GM, Paraskevas F, Glader B, Arber DA, Means RT Jr (eds): Wintrobe's Clinical Hematology, ed 12. Philadelphia, Lippincott/Williams \& Wilkins, 2009, pp 9-10. 